\title{
Antibacterial effect of Allium cepa (onion), Allium sativum (garlic), Azadirachta indica (neem) extract against different bacteria isolated from clinical sample.
}

1. MBBS, M.Phil

Associate Professor Microbiology, Pathology

Sheikh Zayed Medical College

Rahim Yar Khan.

2. MBBS, M.Phil

Associate Professor Pathology

Sheikh Zayed Medical College

Rahim Yar Khan.

3. MBBS, M.Phil

Assistant Professor Pathology

Sheikh Zayed Medical College

Rahim Yar Khan.

4. MBBS

Medical Officer Microbiology

Sheikh Zayed Medical College

Rahim Yar Khan.

5. MBBS, FCPS

Assistant Professor Medicine

Sheikh Zayed Medical College

Rahim Yar Khan.

Correspondence Address:

Dr. Muhammad Shahbaz Hussain

Department of Pathology

Sheikh Zayed Medical College Rahim Yar Khan.

drmshahbaz@szmc.edu.pk

Article received on:

20/04/2020

Accepted for publication:

$13 / 01 / 2021$
Muhammad Shahbaz Hussain', Muhammad Bilal Ghafoor², Umar Khalid Cheema ${ }^{3}$, Muhammad Sajjad ${ }^{4}$, Muhammad Shoaib Akhtar ${ }^{5}$

ABSTRACT... Objective: The objective of this study was to evaluate and screen the antibacterial activity of medicinal plant which were most cultivated in ancient time. Study Design: Experimental Study. Setting: Microbiology Section, Pathology Department, Sheikh Zayed Hospital/Medical College Rahim Yar Khan. Period: February 2019 to May 2019. Material \& Methods: The fresh aqueous extract of garlic cloves (Allium sativum), onion bulb (Allium cepa) and neem (Azadirachta indica) leaves used against the clinically isolated Staphylococcus aureus(S.aureus), Escherichia coli (E.coli), Klebsiella, Acinetobacter and Pseudomonas species by using agar well diffusion method. Aqueous extract of used plant tested at different concentrations of $100 \%, 75 \%, 50 \%, 25 \%$. Results: All these concentrations showed inhibitory effect towards Gram positive bacteria (S.aureus), while Gram negative bacteria more sensitive to higher concentration. In this analysis, on comparison we observed that fresh garlic juice extract was more efficient on all tested bacteria either Gram positive or Gram negative than other and give maximum zone of inhibition on S.aureus $(40 \mathrm{~mm})$ due to their high chemistry. Gram negative bacteria mainly E. coli somehow resistant to onion and neem extract because they possess the ability to rapidly mutate their genetic makeup towards phytochemical compounds. Conclusion: The result of study also elicits that efficacy of fresh extract depends upon concentrations levels. The plant showed maximum zone of inhibition at $100 \%$ than at $25 \%$ because on higher level they contain higher bioactive compounds.

Key words: $\quad$ Allium Cepa (Onion), Allium Sativum (Garlic), Azadirachta Indica (Neem), Agar Well Diffusion Assay, Antibacterial, Extracts, Phytochemicals, Zone of Inhibition.

Article Citation: Hussain MS, Ghafoor MB, Cheema UK, Sajjad M, Akhtar MS. Antibacterial effect of Allium cepa (onion), Allium sativum (garlic), Azadirachta indica (neem) extract against different bacteria isolated from clinical sample. Professional Med J 2021; 28(8):1083-1089.

https://doi.org/10.29309/TPMJ/2021.28.08.4733

\section{INTRODUCTION}

Since the inception of cultivation, the resourceful medicinal plant become the essential and important part of human life. The pharmaceutical analysis of these medicinal plant confesses their value and grant them to serve as key component in synthetic drug formulation. ${ }^{1}$

The $80 \%$ of the world population depends on these sorts of plant whose product encounter their initial medical care need. The data demonstrated by World Health Organisation in $2005 .^{2}$

Now-a-days Multidrug resistance (MDR), extensive drug resistance (XDR), antimicrobial resistance (AMR) are the more common issue in the plant, animal and human infectious agent. ${ }^{3}$ The antimicrobial resistance (AMR) development are due to self-medication and unchecked regime of medicine. Therefore, this problem motivates the medical authorities to screen the wholly plant or specific part of plant for their antimicrobial ability, and then try to discover plant based commercially available drugs.

The natural substances such as plants are found to be more effective against various infections. They show better results and least side effects as compared to commercially available antibiotics.

Garlic is a plant which was investigated over years and used against infections. ${ }^{4}$ Scientific name of 
garlic is Allium sativum, it is the specie of onion family Alliaceae and belongs to order liliales. ${ }^{5}$ Louis pasture firstly discover the antimicrobial property of onion and garlic extracts since then it is investigated and use against various infections. Both gram positive and negative shows susceptibility to garlic juice. ${ }^{6}$ Garlic has antimicrobial property because of many oils and organosulfur compounds that are present in it and they are water-soluble in nature. It contains sulphur compound such as thiosulfate which is mainly responsible for its effectiveness. ${ }^{7}$ If thiosulfate is removed from garlic than it lost its antimicrobial activity. ${ }^{8}$ The intact garlic contains alliin (S-allyl-L-cysteine sulfoxide). Allin is a soluble, crystal, odourless compound. ${ }^{9}$ When garlic is crushed, alliinase enzyme activates which convert alliin into allicin. ${ }^{10}$ Allicin is the precursor of sulphur-containing compounds, characteristic odour and pharmacological properties are due to this compound. Allicin is further converted into diallyl disulphide, and the reduction by cysteine will disrupt the disulphide bond in microbial proteins and thus it kills them. ${ }^{11}$ Allicin exhibits its antimicrobial activity mainly by completely damage to the synthesis of RNA, DNA and protein synthesis is also disturb but not completely, so RNA is the main target for allicin to act. ${ }^{12}$ Allicin is very unstable and immediately degrade. ${ }^{13}$ A typical bulb contains almost $1 \%$ allicin. ${ }^{14}$ Published research articles show that the extract of raw garlic effective against many pathogenic bacteria ${ }^{15}$, even against the strains that have become resistant to antibiotics. ${ }^{16}$ Researches have also indicated that garlic has anti-neoplastic, cardiovascular, immunestimulatory and hypoglycaemic properties. ${ }^{17}$

Allium family one of the vital groups of vegetable that is freshly cultivated over the centuries. This family have $660^{18}$ or more species that are differ in appearance (colour and shape) and in taste, although they have same phytochemical compounds. Allium cepa (onion) and Allium sativum (garlic) are the most common member of allium family. ${ }^{19}$

The generic name is onion for Allium cepa (A.cepa) and is oldest growing plant which has many nutritional as well as antioxidants and antimicrobial properties. Due to its antibacterial property it is extensively studied. It has minute quantity of vitamins and enough quantity of minerals. A.cepa as both food and medicine.

For medical attention, the fresh uncooked onion bulbs are used because on boiling or on heating they lose their working efficiency against infectious agent. The biological related components present are allinin, seleno, flavonoids, anthocyanins and sulphur but there is ambiguity regarding their mode of action. ${ }^{20}$

Theabovemention high number of phytochemicals in onion bulb can be used against diabetes, hypertension, and infectious pathogen. Allicin use specifically against food borne pathogen. They also have ability to treat asthma, cough, and sore throat or act as antibacterial, antioxidant..1,22 So, these onion bulbs possess enough efficacy to cure various type of disease or infection.

In ancient time the folk healer used A.cepa bulbs against the pathogenic infection and later on World Health Organisation (WHO) delineate the medical care of onion bulbs. ${ }^{22}$ A.cepa work actively against E.coli, Pseudomonas aeruginosa, Klebsiella species and mainly against Methicillin resistance Staphylococcus aureus (MRSA). ${ }^{23}$

The neem plant scientific name Azadirachata indica (A.indica), belong to meliaceae family, usually known as neem tree. It is popular in India and its neighbourhood regions.Neem is the versatile tree and it serve as traditional therapeutic agent. ${ }^{24}$ The resourceful part of neem plant use to control many health-related disorders in human body. ${ }^{25} \mathrm{~A}$ little water and enough sunlight require for the growth of A.indica. ${ }^{26}$ The chemistry of neem plant evaluates their medical applications.

The neem plant medical attention is approved to treat variety of infection more likely bacterial infection. Most bacterial infections show resistance to antibiotics. For that reason, the experimentation of this typical tree had done against various type of pathogen and these medicinal plants are affordable than the commercially available drugs. 
The neem leaves and other parts like bark and seed oil act as antibacterial, antioxidant and have ability to cure fungal, malarial, and inflammatory infections. The components of neem plant parts mainly the leave extract compounds have immense potential against Staphylococcus aureus, a bacterial infectious agent that cause majority of skin disease and familiar with the resistant to Methicillin resistance Staphylococcus aureus (MRSA). ${ }^{27}$

Our study mainly had two parts. First, we collected the medicinal plant and made their paste. Secondly, tested them on multidrug resistant organisms. In Pakistan l.e., third world country, these herbal medicines are more affordable than synthetic drugs. Therefore, the purpose of our experimental research was; To evaluate the role of medicinal plant in most multidrug resistant clinical pathogen.

\section{MATERIAL \& METHODS}

This was experimental research design and held in Microbiology section, Pathology department, Sheikh Zayed Hospital/Medical College Rahim Yar Khan. It took approximately 3 months from February 2019 to May 2019. The study was approved by ethical committee (REF.56/52mc/52H).

\section{Collection of Fresh Plant Materials}

Garlic cloves and onion bulbs were purchased from ordinary market of Rahim Yar Khan. Neem leaves were collected from house garden Neem tree.

\section{EXTRACTS PREPARATION}

\section{Preparation of fresh garlic bulbs extract}

Fresh garlic cloves collected and weighed them properly. It was about $500 \mathrm{~g}$. Peeled them and washed with sterilized distilled water. Then sterilized the chopper with proper disinfectant i.e., ethanol and chopped in pestle and mortar aseptically. Then this extract was filtered by gauze piece. The filtrate was $100 \%$ pure extract of fresh garlic. And stored at $-10^{\circ} \mathrm{C}$.
Preparation of fresh neem leave aqueous extract

Fresh Neem leaves weighed i.e., $250 \mathrm{~g}$ soon after collection, cut them into small pieces, washed with sterile distilled water to reduce the dirt. Then soaked in sterile water over a night. The soaked leaves along with water in which leaves were soaked were grind in electrical grinder aseptically. A paste is formed which is $100 \%$ pure aqueous extract of fresh Neem leaves. Stored in sterile container at refrigerated temperature $\left(4^{\circ} \mathrm{C}\right) \cdot{ }^{27}$

Preparation of fresh purple onion bulb extract Fresh Purple onion collected it was about 500g, peeled them, washed with sterile distilled water, cut the onion bulbs into small pieces and chopped in pestle mortar with proper aseptic techniques. The extract obtained, same as garlic extract it was filtered by gauze piece and filtrate is $100 \%$ pure onion extract. It was stored at $4^{\circ} \mathrm{C}$.

\section{Bacterial Isolation}

Five multidrug resistant bacteria were used to check susceptibility against medicinal plants which were Pseudomonas, E. coli, Klebsiella, Acinetobacter, Staphylococcus aureus.

Bacteria were isolated from clinical samples from different indoor and outdoor patients in a tertiary care hospital of Rahim Yar Khan. After isolation they were identified by colony morphology, Gram staining and confirmed by different biochemical tests and RapID TM ONE SYSTEM. After confirmation they were sub cultured on blood and MacConkey agar for pure growth and incubated for 24 hours at 37 degree Celsius. And preserved them until our study completed.

\section{Dilution of Concentration}

The dilution of original $100 \%$ pure extract were made, and these were $75 \%, 50 \%, 25 \%$. They were made by adding distilled water in pure extracts in appropriate volume.

\section{Inoculum Preparation}

$3 \mathrm{ml}$ of normal saline is added in test tube and a pure colony of required isolated bacteria is mixed thoroughly in it and compared by $0.5 \mathrm{M}$ MacFarland. Inoculum is prepared by $0.5 \mathrm{M}$ 
MacFarland. This procedure repeated for each organism.

\section{Antibacterial Well Diffusion Assay}

$500 \mathrm{ml}$ of Muller-Hinton agar was prepared and poured in petri plates. After solidification of media, a sterile swab is dipped in inoculum and swabbed on media in 3 ways. Wells were made with the help of well puncture $8 \mathrm{~mm}$ for each organism aseptically. 40ul of fresh extract were poured with the help of micropipette dispenser in wells as $100 \%$ in well labelled $1,75 \%$ in well labelled 2, 50\% in well labelled 3 and $25 \%$ in well labelled 4. Imipenem is placed on each plate for control. Plates were incubated in upright position in incubator for 24 hours at 37 degree Celsius.

\section{RESULTS}

In this study, effectiveness of antibacterial activity of fresh plant extracts measured by measuring zone of inhibition around the well on inoculated agar media. Results are shown in following figures.

Figure-1 shows the inhibitory effect of garlic (Allium sativum) extract of different concentrations against clinical organisms. All organisms are susceptible to the fresh garlic extracts. However, Staphylococcus aureus has greater inhibitory effects as it show a big zone of inhibition even at lower concentration (25\%).

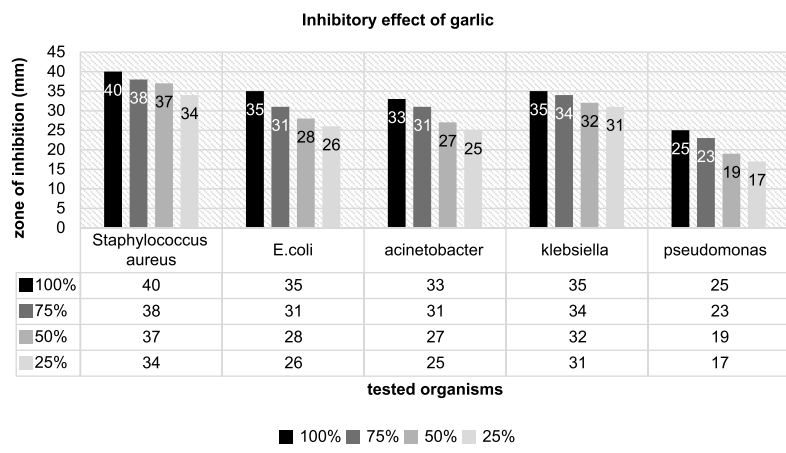

Figure-1. Inhibitory effect of fresh garlic extracts.

Figure-2 shows the effectiveness of fresh neem extracts at different concentrations on the tested organisms. It shows that Staphylococcus aureus, Pseudomonas, and Acinetobacter shows susceptibility to the neem extract. While all other which includes Klebsiella and E. coli which are resistant to neem extracts. The minimum effective concentration of neem against Staphylococcus is $25 \%$ while for Pseudomonas effective concentration is $75 \%$ below which it is ineffective.

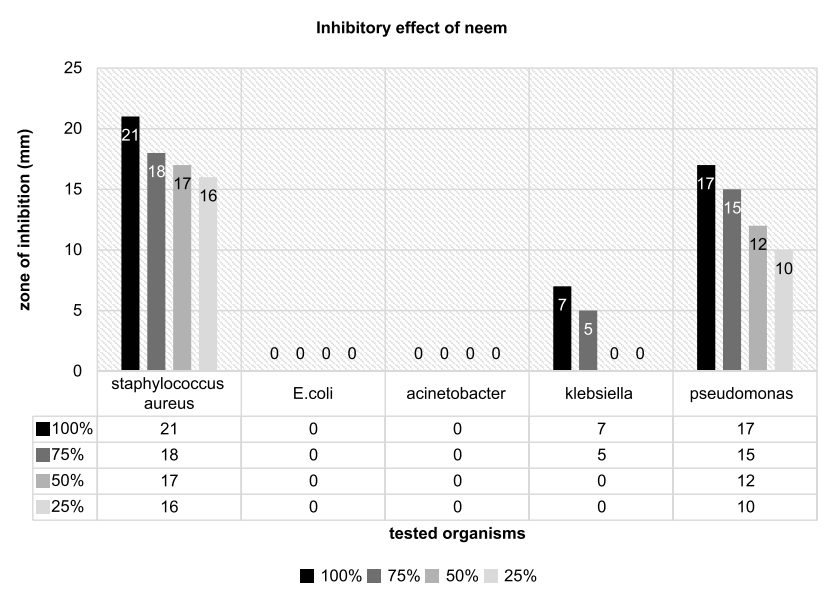

Figure-2. Inhibitory effect of neem.

Figure-3 shows the effectiveness of onion extracts. Staphylococcus aureus has zone of inhibition even at $50 \%$ while Klebsiella and Acinetobacter has very narrow zone of inhibition for onion. E.coli is ineffective against onion extracts. Pseudomonas show narrow zone only at $100 \%$ concentration.

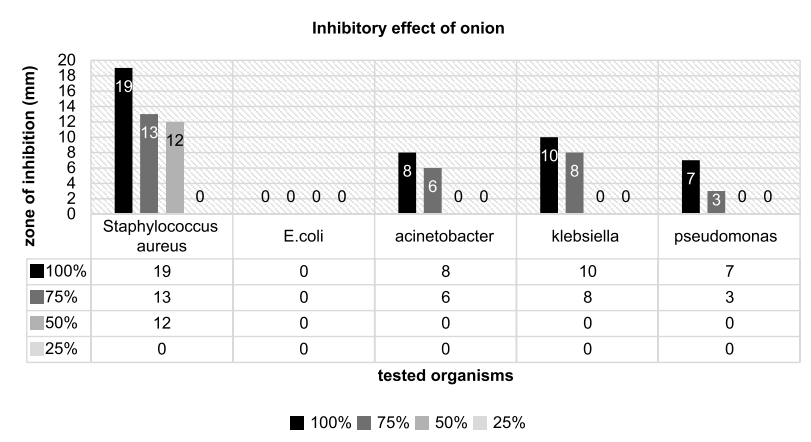

Figure-3. Inhibitory effect of onion.

\section{DISCUSSION}

The present experimental study determines the plant based antibacterial efficacy against multidrug resistant bacterial pathogen and the tested organism are Staphylococcus aureus, Pseudomonas aeruginosa, Klebsiella species, Escherichia coli, Acinetobacter species. The resistance of antibiotics considers as a major problem and this led to development of medicinal 
plant, which has ability to work as antibacterial agent with highlighted efficiency. It is the secondary metabolite products that actually have the beneficial activity against bacteria and other microbes.

According to this study, tested bacteria showed high susceptibility to fresh garlic juice can be used both against Gram positive and Gramnegative bacteria. Broad spectrum antibacterial effect of garlic is mainly due to Allicin and its compounds in pure form (fresh extract). For every antibacterial active substance, it must act on thick layer of peptidoglycan in Gram positive bacteria so that peptidoglycan damaged and cellular compounds come out of the cell and cell shrinks and die. But for Gram negative bacteria, there is an outer layer in addition to the peptidoglycan, so any antibacterial substance must act on this outer layer, it dissolved, or this active agent must create pores in cell membrane, ions and bacterial cell leak out and cell die. From this study it is inferred that allicin is active compound against Staphylococcus aureus which is Gram positive as well as pseudomonas, Klebsiella, E. coli and Acinetobacter. Allicin is active even at lower concentration as $25 \%$. If allicin is use with an antibiotic such as imipenem, its effect increases as it shows synergic effect with antibiotic against the staphylococcus aureus. So, it is more suitable than antibiotics as it shows better effect against multi drug resistant bacteria. Basically, this experimental study shows the beneficial use of Allium sativum against diseases that are caused by MDR bacteria. As because antimicrobial resistance increases worldwide so this study is urgent need and interest.

In our research design, onion (A.cepa) used against these tested organisms. The results which observed showed some variation and some similarities from the study which we followed. Onion had same antibacterial efficacy against E. coli pseudomonas and Klebsiella that is. Somehow resistant to fresh aqueous extract of onion bulb. While Allium cepa had much more antibacterial activity for Staphylococcus aureus. It might be due to the presence of variant type of phytochemical compound in onion bulb.
Flavonoids, polyphenols serve as broad spectrum components. Polyphenolic components mainly reported as antimicrobial element. Onion components have less efficacy to gram negative bacteria. Therefore, it significantly inhibited the Gram-positive staphylococcus aureus and on this onion bulb efficacy are much better than the study we followed. Quercetin molecule in onion also useful in to treat those bacterial infection.

In this experimental research medical care of aqueous neem extract also investigated against the same tested pathogen and result represented in table and graphs as above. Staphylococcus aureus and Pseudomonas aeruginosa exhibited sensitivity on all high to low concentration of aqueous neem leaves extract. While Escherichia coli and Acinetobacter species showed resistance to neem extract same as the study which we followed. Klebsiella species have shown minor zone to this extract. This lower efficacy of neem leaves to mostly Gram negative, because that type bacteria have astonishing ability to mutate their genetic makeup and elicit resistance mechanism. Generally, their cell wall also alters their structure, or some time produces such enzymes which not attach them to component of synthetic drug. ${ }^{27}$

So, some of tested Gram-negative organism showed same resistant phenomenon to neem extract. The positive result to neem leaf is due to presence of diverse biological component that is quercetin, b-sitosterol and azadirachtins.

The negative result of medicinal plant during this study did not means that plant lack bioactive component nor consider them as inactive plant. It might be possible that active components are present in lesser or insufficient form amount in tested extract. It was also observed that on low extract concentration bacteria able to grow but with higher concentration tested organism become sensitive to all fresh plant aqueous extract (garlic cloves, onion bulb and neem leaf).

\section{CONCLUSION}

This research was based on the susceptibility of different Gram positive and Gram negative bacteria to the fresh extract of three medicinal 
plants naming Onion (A.cepa), Garlic (A.sativum), Neem (A.indica). All extracts have antibacterial activity at different concentrations. Researchers investigate to discover or synthesized new antibiotic, but bacteria mutate and got resistance to that antibiotic. Antimicrobial resistant, therefore worldwide problem, so it may be an alternative method for the treatment of multi drug resistant bacteria. No resistance is found against garlic and it also have synergic effect with antibiotics, so studies should be done to evaluate its use as antibiotic/garlic combination against MDR bacteria. Studies should also be done to evaluate which phytochemicals are present in Neem which serve as antibacterial agent. Moreover, proper dosage and dilution of crude extract of plants should be found for its clinical use.

\section{Copyright $@ 13$ Jan, 2021.}

\section{REFERENCE}

1. Yuan HW, Ma LX, Qi DD, Zhang P, Li CH, Zhu J. The historical development of deqi concept from classics of traditional Chinese medicine to modern research: Exploitation of the connotation of deqi in Chinese medicine. Evidence-Based Complementary and Alternative Medicine. 2013; 2013.

2. Ekor M. The growing use of herbal medicines: Issues relating to adverse reactions and challenges in monitoring safety. Frontiers in pharmacology. 2014 Jan 10; 4:177.

3. Odonkor ST. Radiation sensitivity and molecular characterization of water-borne multidrug resistant escherichia coli (Doctoral dissertation). 2015.

4. Gebreyohannes G, Gebreyohannes M. Medicinal values of garlic: A review. International Journal of Medicine and Medical Sciences. 2013 Sep; 5(9):401-8.

5. Upadhyay RK. Garlic: A potential source of pharmaceuticals and pesticides: $A$ review. International Journal of Green Pharmacy (IJGP). 2016 Mar 20; 10(1).

6. Essien UC, Odineze OM, Sheyin Z, Ede FR, Vem TS. Antibacterial activity of different concentrations of garlic (allium sativum) extract on some bacteria isolated from clinical. SAMPLE. 2017.

7. Santhosha SG, Jamuna P, Prabhavathi SN. Bioactive components of garlic and their physiological role in health maintenance: A review. Food Bioscience. 2013 Sep 1; 3:59-74.
8. Ryu JH, Kang D. Physicochemical properties, biological activity, health benefits, and general limitations of aged black garlic: A review. Molecules. 2017 Jun; 22(6):919. Acteria isolated from clinical specimens. 2017.

9. Wen YD, Wang $H$, Zhu $Y Z$. The drug developments of hydrogen sulfide on cardiovascular disease. Oxidative medicine and cellular longevity. 2018; 2018.

10. Majewski M. Allium sativum: Facts and myths regarding human health. Roczniki Państwowego Zakładu Higieny. 2014; 65(1).

11. Borlinghaus J, Albrecht F, Gruhlke MC, Nwachukwu ID, Slusarenko AJ. Allicin: chemistry and biological properties. Molecules. 2014 Aug; 19(8):12591-618.

12. Wink M. Modes of action of herbal medicines and plant secondary metabolites. Medicines. 2015 Sep; 2(3):251-86.

13. Majewski M. Allium sativum: Facts and myths regarding human health. Roczniki Państwowego Zakładu Higieny. 2014; 65(1).

14. Wallock-Richards D, Doherty CJ, Doherty L, Clarke DJ, Place M, Govan JR, Campopiano DJ. Garlic revisited: antimicrobial activity of allicin-containing garlic extracts against Burkholderia cepacia complex. PLoS One. 2014; 9(12).

15. Yadav S, Trivedi NA, Bhatt JD. Antimicrobial activity of fresh garlic juice: An in vitro study. Ayu. 2015 Apr; 36(2):203.

16. Li G, Ma X, Deng L, Zhao X, Wei Y, Gao Z, Jia J, Xu J, Sun C. Fresh garlic extract enhances the antimicrobial activities of antibiotics on resistant strains in vitro. Jundishapur journal of microbiology. 2015 May; 8(5).

17. Gorji A. Garlic: A review of potential therapeutic effects. Avicenna Journal of Phytomedicine - March 2014.

18. Suleria HA, Butt MS, Anjum FM, Saeed F, Khalid N. Onion: Nature protection against physiological threats. Critical reviews in food science and nutrition. 2015 Jan 2; 55(1):50-66.

19. Sharifi-Rad J, Mnayer D, Tabanelli G, Stojanović-Radić ZZ, Sharifi-Rad M, Yousaf Z, Vallone L, Setzer WN, Iriti M. Plants of the genus Allium as antibacterial agents: From tradition to pharmacy. Cellular and Molecular Biology. 2016 Aug 29; 62(9):57-68.

20. S Bisen P, Emerald M. Nutritional and therapeutic potential of garlic and onion (Allium sp.). Current Nutrition \& Food Science. 2016 Aug 1; 12(3):190-9. 
21. Teshika JD, Zakariyyah AM, Zaynab T, Zengin G, Rengasamy KR, Pandian SK, Fawzi MM. Traditional and modern uses of onion bulb (Allium cepa L.): A systematic review. Critical reviews in food science and nutrition. 2019 Jun 27; 59(sup1): S39-70.

22. Kabrah MA, Faidah HS, Ashshi AM, Turkistani MS. Antibacterial effect of onion. Sch J App Med Sci. 2016; 4:4128-33.

23. Kumar VS, Navaratnam V. Neem (Azadirachta indica): Prehistory to contemporary medicinal uses to humankind. Asian Pacific journal of tropical biomedicine. 2013 Jul 1; 3(7):505-14.

24. Kumar VS, Navaratnam V. Neem (Azadirachta indica): Prehistory to contemporary medicinal uses to humankind. Asian Pacific journal of tropical biomedicine. 2013 Jul 1; 3(7):505-14.
25. Tiwari R, Verma AK, Chakraborty S, Dhama K, Singh SV. Neem (Azadirachta indica) and its potential for safeguarding health of animals and humans: A review. Journal of Biological Sciences. 2014 Feb 15; 14(2):110-23.

26. Ogbuewu IP, Odoemenam VU, Obikaonu HO, Opara MN, Emenalom OO, Uchegbu MC, Okoli IC, Esonu $B O$, lloeje $M U$. The growing importance of neem (Azadirachta indica A. Juss) in agriculture, industry, medicine and environment: A review. Res $\mathrm{J}$ Med Plant. 2011 Oct; 5(3):230-45.

27. Francine $U$, Jeannette $U$, Pierre RJ. Assessment of antibacterial activity of neem plant (Azadirachta indica) on Staphylococcus aureus and Escherichia coli. J Med Plants Stud. 2015; 3(4):85-91.

\begin{tabular}{|c|l|l|l|}
\hline \multicolumn{3}{|c|}{ AUTHORSHIP AND CONTRIBUTION DECLARATION } \\
\hline Sr. \# & \multicolumn{1}{|c|}{ Author(s) Full Name } & \multicolumn{1}{|c|}{ Contribution to the paper } & Author(s) Signature \\
\hline 1 & M. Shahbaz Hussain & $\begin{array}{l}\text { Principal Investigator and } \\
\text { main idea. } \\
\text { Literature review and } \\
\text { discussion. } \\
\text { Interpretation of data and } \\
\text { drafting. } \\
\text { Data collection and statistics. }\end{array}$ \\
\hline 4 & M. Bilal Ghafoor & Umar Khalid Cheema & $\begin{array}{l}\text { Muhammad Sajjad } \\
\text { Critical review and } \\
\text { finalization. }\end{array}$ \\
\hline 5 & M. Shoaib Akhtar & \\
\hline
\end{tabular}

